\title{
MODEL PENYEBARAN PENYAKIT TUBERKULOSIS DENGAN KONTROL VAKSINASI
}

\author{
RINDI WULANDARI TANJUNG, MUHAFZAN*, ZULAKMAL \\ Program Studi S1 Matematika, \\ Fakultas Matematika dan Ilmu Pengetahuan Alam, Universitas Andalas, \\ Kampus UNAND Limau Manis Padang, Indonesia. \\ email : rindiwlndr0798@gmail.com,muhafzan@sci.unand.ac.id,zulakmal@sci.unand.ac.id
}

Diterima 12 Juni $2021 \quad$ Direvisi 22 Juni 2021 Dipublikasikan 26 Juli 2021

\begin{abstract}
Abstrak. Dalam artikel ini dipelajari model penyebaran penyakit tuberkulosis dalam bentuk model kontrol optimal dengan vaksinasi dijadikan sebagai variabel pengontrol. Model penyebaran penyakit tuberkulosis tersebut dibagi atas empat kompartemen, yaitu Susceptible, Infective, Treatment dan Recovery. Masalah yang diselesaikan adalah mendapatkan level vaksinasi optimal yang memenuhi konstrain model dinamika penyebaran penyakit tuberkulosis sedemikian sehingga jumlah populasi terinfeksi diminimalkan. Suatu simulasi numerik menggunakan metode Runge Kutta orde 4 diimplementasikan untuk melihat dinamika populasi Susceptible, Infective, Treatment dan Recovery setiap waktu.
\end{abstract}

Kata Kunci: Model SITR, Kontrol Optimal, Metode Runge Kutta

\section{Pendahuluan}

Tuberkulosis merupakan penyakit menular yang umum, dan dalam banyak kasus bersifat mematikan yang disebabkan oleh Mycrobacterium Tuberculosis. Penyakit TBC menular dengan cepat melalui udara saat seorang penderita TBC bersin atau batuk [9]. Untuk mengetahui penyebaran penyakit TBC, model matematika dapat digunakan sebagai suatu alternatif dalam merepresentasikan permasalahan yang terjadi dengan tujuan untuk menekan penyebaran penyakit tersebut.

Model matematika penyebaran penyakit Tuberkulosis yang dibahas dalam penelitian ini adalah model epidemik SITR (Susceptible-Infective-TreatmentRecovered). Analisis model SITR untuk penyebaran penyakit Tuberkulosis telah dikembangkan oleh beberapa peneliti, lihat [4], [7] untuk lebih detail. Dalam penelitian [7] juga membahas tentang kontrol optimal yang berkaitan dengan pemberian vaksinasi.

Dalam artikel ini model yang dibahas berupa suatu model SITR dengan menambahkan variabel kontrol vaksinasi pada populasi Susceptible yang bertujuan agar

*Penulis Korespondensi 
populasi yang sembuh meningkat. Selain itu, akan dilakukan analisis kestabilan untuk mengetahui apakah suatu penyakit menyebar atau menghilang dari suatu populasi, dan kontrol optimal dengan menentukan suatu fungsi tujuan yang dapat meminimumkan populasi terinfeksi dan meminimalkan biaya vaksinasi. Selanjutnya akan dilakukan simulasi dari penyelesaian numerik dengan metode Runge Kutta menggunakan MATLAB.

\section{Landasan Teori}

\subsection{Sistem Persamaan Diferensial orde 1 dan Kestabilannya}

Sistem persamaan diferensial orde 1 adalah kumpulan dari beberapa persamaan diferensial orde satu. Secara umum, sistem persamaan diferensial dapat ditulis sebagai berikut:

$$
\dot{\mathbf{x}}=\mathbf{f}(\mathbf{x}, \mathbf{u})
$$

Jika fungsi f linier maka persamaan (2.1) disebut sistem persamaan diferensial linier, dalam hal sebaliknya disebut sistem persamaan diferensial nonlinier. Dalam hal f linier, sistem (2.1) dapat ditulis sebagai

$$
\dot{\mathbf{x}}=A \mathbf{x}, \quad A \in \mathbb{R}^{n \times n} .
$$

Salah satu kajian untuk sistem persamaan diferensial adalah kestabilan titik ekuilibrium.

Definisi 2.1. [3] Suatu titik $\mathbf{x}_{e} \in \mathbb{R}^{n}$ dikatakan titik ekuilibrium dari sistem (2.1) jika $\mathbf{f}\left(\mathbf{x}_{e}, \mathbf{0}\right)=\mathbf{0}$.

Definisi 2.2. [8] Perhatikan sistem persamaan (2.1)

(1) Suatu titik ekuilibrium $\mathbf{x}_{e}$ untuk (2.1) dikatakan stabil pada $t=t_{0}$ jika untuk setiap $\varepsilon>0$, terdapat $\delta>0$ sedemikian sehingga $\left\|\mathbf{x}\left(t_{0}\right)-\mathbf{x}_{e}\right\|<\delta \Rightarrow\left\|\mathbf{x}(t)-\mathbf{x}_{e}\right\|<\varepsilon \quad$ untuk semua $t \geq t_{0}$

(2) Suatu titik ekuilibrium $\mathbf{x}_{e}$ untuk (2.1) dikatakan stabil asimtotik pada $t=t_{0}$ jika ia stabil dan terdapat $\delta_{1}>0$ sedemikian sehingga $\left\|\mathbf{x}\left(t_{0}\right)-\mathbf{x}_{e}\right\|<\delta_{1} \Rightarrow$ $\lim _{t \rightarrow \infty}\left\|\mathbf{x}(t)-\mathbf{x}_{e}\right\|=0$.

Teorema 2.3. [1] Untuk sistem persamaan diferensial linier (2.2) $\operatorname{dengan} \operatorname{det}(A) \neq$ 0 , titik ekuilibrium $\mathbf{x}_{e}=\mathbf{0}$ adalah

(1) Stabil jika dan hanya jika bagian riil dari semua nilai eigen A adalah non positif.

(2) Stabil asimtotik jika dan hanya jika bagian riil dari semua nilai eigen A adalah negatif.

Jika sistem (2.1) nonlinier, maka kestabilan titik ekuilibriumnya dapat diperiksa dengan melinierkan sistem nonlinier tersebut di sekitar titik ekuilibrium $\mathbf{x}_{e}$ dengan 
menggunakan ekspansi deret Taylor [1]. Matriks

$$
J=\left(\begin{array}{cccc}
\frac{\partial f_{1}}{\partial x_{1}} & \frac{\partial f_{1}}{\partial x_{2}} & \cdots & \frac{\partial f_{1}}{\partial x_{n}} \\
\frac{\partial f_{2}}{\partial x_{1}} & \frac{\partial f_{2}}{\partial x_{2}} & \cdots & \frac{\partial f_{2}}{\partial x_{n}} \\
\vdots & \vdots & \ddots & \vdots \\
\frac{\partial f_{n}}{\partial x_{1}} & \frac{\partial f_{n}}{\partial x_{2}} & \cdots & \frac{\partial f_{n}}{\partial x_{n}}
\end{array}\right)_{x=x_{e}}
$$

merupakan matriks Jacobian dari fungsi $\mathbf{f}(\mathbf{x})$ disekitar titik ekuilibrium $\mathbf{x}_{e}$

Teorema 2.4. [3] Misalkan $\mathbf{x}_{e}$ adalah titik ekuilibrium dari sistem nonlinear (2.1) dan $J$ adalah Jacobian $\mathbf{f}$ di titik $\mathbf{x}_{e}$. Titik ekuilibrium $\mathbf{x}_{e}$ adalah stabil asimtotik jika bagian riil dari semua nilai eigen matriks Jacobian adalah negatif.

\subsection{Model Dasar Penyebaran Penyakit Tuberkulosis}

Model matematika penyebaran penyakit Tuberkulosis berdasarkan pada penelitian yang dilakukan oleh Side, dkk. [7]:

$$
\begin{aligned}
& \dot{S}=b N-\beta \frac{I}{N} S-\mu S, \\
& \dot{I}=\beta \frac{I}{N} S-\alpha I-\mu I, \\
& \dot{T}=\alpha I-\gamma T-\mu T, \\
& \dot{R}=\gamma T-\mu R,
\end{aligned}
$$

dengan total populasi, $\quad N=S+I+T+R$.

Dalam model (2.4) terdapat parameter $b$ yang menyatakan laju kelahiran, $\mu$ adalah laju kematian, $\beta$ adalah laju penyebaran, $\alpha$ adalah pemberian obat, $\delta$ menyatakan laju kesembuhan alami dan $\gamma$ menyatakan laju kesembuhan.

Bilangan reproduksi dasar biasa disebut juga parameter ambang untuk menentukan batas antara kepunahan dan penyebaran suatu wabah penyakit. Dalam [5] Rost dan $\mathrm{Wu}$, memberikan teorema tentang hubungan bilangan reproduksi dasar dengan kestabilan titik ekuilibrium.

Teorema 2.5. [8]

(1) Jika $\Re_{0}<1$ maka titik ekuilibrium bebas penyakit adalah stabil asimtotik dan jika $\Re_{0}>1$ maka titik ekuilibrium bebas penyakit tidak stabil .

(2) Jika $\Re_{0}>1$ maka titik ekuilibrium endemik adalah stabil asimtotik .

(3) Jika $\Re_{0}>1$ maka penyakit tersebut akan meningkat menjadi wabah (endemik) dan jika $\Re_{0}<1$ maka penyakit tersebut akan menghilang.

\subsection{Masalah Kontrol Optimal}

Kontrol optimal merupakan suatu metode optimasi matematika yang digunakan untuk mendapatkan suatu pengontrol yang memenuhi suatu sistem persamaan diferensial dan mengoptimalkan suatu fungsi tujuan [2]. 
Secara umum, formulasi masalah kontrol optimal diberikan sebagai berikut. Diberikan suatu fungsi objektif

$$
J(u)=S\left(x\left(T_{f}\right), T_{f}\right)+\int_{t_{0}}^{T_{f}} F(x, u, t) d t,
$$

dan suatu sistem persamaan diferensial

$$
\dot{x}=f(x, u, t), \quad x\left(t_{0}\right)=x_{0}, \quad x\left(T_{f}\right) \text { bebas, }
$$

Definisikan fungsi Hamiltonian berikut [6]:

$$
H(x, u, q, t)=F(x, u, t)+q f(x, u, t) .
$$

Syarat perlu agar $u^{*}$ mengoptimalkan $J$, yaitu [6]:

$$
\begin{aligned}
& \frac{\partial H}{\partial u}=0 \\
& \dot{q}=-\frac{\partial H}{\partial x} \\
& q\left(T_{f}\right)=\frac{\partial S\left(x\left(T_{f}\right), T_{f}\right)}{\partial x\left(T_{f}\right)} .
\end{aligned}
$$

Dalam [6] dinyatakan bahwa syarat cukup agar $u^{*}$ memaksimumkan $J$ adalah $\frac{\partial^{2} H}{\partial u^{2}}<0$ dan meminimumkan $J$ adalah $\frac{\partial^{2} H}{\partial u^{2}}>0$.

\section{Model Penyebaran Penyakit Tuberkulosis dengan Kontrol Vaksinasi}

\subsection{Analisis Kestabilan Model}

Untuk menganalisa kestabilan pada model penyakit Tuberkulosis, akan dicari titik ekuilibrium pada persamaan (2.4). Sehingga diperoleh titik ekuilibrium bebas penyakit $E^{0}=\left(\frac{b N}{\mu}, 0,0,0\right)$ dan titik ekuilibrium endemik, yaitu $E^{*}=$ $\left(S^{*}, I^{*}, T^{*}, R^{*}\right)$ dengan:

$$
\begin{aligned}
S^{*} & =\frac{(\mu+\alpha) N}{\beta} \quad I^{*}=\frac{(\beta b-\mu(\mu+\alpha)) N}{\beta(\mu+\alpha)}, \\
T^{*} & =\frac{(\beta b-\mu(\mu+\alpha)) \alpha N}{\beta(\mu+\alpha)(\gamma+\mu)}, R^{*}=\frac{\gamma \alpha N(\beta b-\mu(\mu+\alpha))}{\mu \beta(\mu+\alpha)(\gamma+\mu)} .
\end{aligned}
$$

Selanjutnya akan dicari bilangan reproduksi dasar $\left(\Re_{0}\right)$ pada model penyebaran Tuberkulosis (2.4) dengan mengasumsikan $I^{*}>0$. Sehingga didapat nilai reproduksi dasar yaitu, $\Re_{0}=\frac{\beta b}{\mu(\mu+\alpha)}$. Selanjutnya untuk menentukan kestabilan dari sistem (2.4) di titik-titik ekuilibrium $E^{0}$ dan $E^{*}$, maka sistem tersebut perlu dilinierisasi terlebih dahulu menggunakan matriks Jacobian. Berdasarkan persamaan (2.3), maka matriks Jacobian dari sistem (2.4 ) adalah

$$
J=\left[\begin{array}{cccc}
-\frac{\beta I}{N}-\mu & -\frac{\beta S}{N} & 0 & 0 \\
\frac{\beta I}{N} & \frac{\beta S}{N}-\mu-\alpha & 0 & 0 \\
0 & \alpha & -\gamma-\mu & 0 \\
0 & 0 & \gamma & -\mu
\end{array}\right] .
$$


284 Rindi Wulandari Tanjung dkk.

Lalu dengan mensubstitusikan titik ekuilibrium bebas penyakit $E^{0}$ kedalam matriks Jacobian, sehingga diperoleh persamaan sebagai berikut:

$$
\begin{array}{r}
\quad\left(\frac{\beta b}{\mu}-\mu-\alpha-\lambda\right)(-\mu-\lambda)(-\gamma-\mu-\lambda)(-\mu-\lambda)=0 . \\
\lambda_{1}=-\mu, \quad \lambda_{2}=-\mu, \quad \lambda_{3}=-\mu-\gamma, \quad \lambda_{4}=\frac{\beta b}{\mu}-\mu-\alpha .
\end{array}
$$

Dapat dilihat bahwa nilai eigen $\lambda_{1}, \lambda_{2}, \lambda_{3}<0$. Berdasarkan kriteria kestabilan, titik ekuilibrium $E^{0}$ stabil asimtotik jika $\lambda_{4}<0$. Jika $\lambda_{4}<0$ dioperasikan maka diperoleh $\Re_{0}<1$. Jadi dapat disimpulkan bahwa titik ekuilibrium $E^{0}$ stabil asimtotik jika $\Re_{0}<1$.

Selanjutnya akan dilakukan analisis kestabilan dengan mensubstitusikan titik ekuiibrium endemik kedalam matriks Jacobian, sehingga diperoleh persamaan sebagai berikut:

$$
\begin{gathered}
(-\mu-\lambda)(-\gamma-\mu-\lambda)\left(\lambda^{2}+\left(\frac{\beta b}{\mu+\alpha}\right) \lambda+(\beta b-\mu(\mu+\alpha))\right)=0 \\
\lambda_{1}=-\mu, \quad \lambda_{2}=-\mu-\gamma
\end{gathered}
$$

Dapat dilihat bahwa nilai eigen $\lambda_{1}, \lambda_{2}<0$, sedangkan nilai eigen $\lambda_{3}$ dan $\lambda_{4}$ bergantung pada nilai diskriminan

$$
D=\left(\frac{\beta b}{\mu+\alpha}\right)^{2}-4(\beta b-\mu(\mu+\alpha)) \text {. }
$$

Berdasarkan kriteria kestabilan, titik ekuilibrium $E^{*}$ akan stabil asimtotik jika nilai $\lambda_{3}, \lambda_{4}<0$. Maka syarat yang memenuhi agar nilai eigen yang bagian realnya bernilai negatif adalah jika $\sqrt{D}<\frac{\beta b}{\mu+\alpha}$ sehingga diperoleh $\Re_{0}>1$. Dengan demikian $\lambda_{1}$, $\lambda_{2}, \lambda_{3}$ dan $\lambda_{4}$ bernilai negatif artinya jika $\Re_{0}>1$ maka titik ekuilibrium $E^{*}$ stabil asimtotik.

\subsection{Pengaruh Kontrol Vaksinasi}

Pada Model (2.4), model matematika penyebaran pernyakit Tuberkulosis dapat direkonstruksi dengan menambahkan variabel kontrol optimal yaitu berupa pemberian vaksin yang bertujuan dapat mengendalikan penyakit Tuberkulosis. Diasumsikan bahwa vaksin diberikan kepada kelas individu rentan (Susceptible). Misalkan $u$ menyatakan tingkat vaksinasi yang diberikan dengan $0 \leq u \leq 1$.

Model penyebaran penyakit Tuberkulosis dengan kontrol vaksinasi diberikan oleh sistem persamaan persamaan diferensial nonlinier berikut:

$$
\begin{aligned}
& \dot{S}=b N-\beta \frac{I}{N} S-u S-\mu S, \\
& \dot{I}=\beta \frac{I}{N} S-(\mu+\alpha) I, \\
& \dot{T}=\alpha I-\gamma T-\mu T, \\
& \dot{R}=u S+\gamma T-\mu R,
\end{aligned}
$$


dengan parameter-parameter $b, \mu, \beta, u, \alpha, \gamma \geq 0$ [7]. Fungsi tujuan yang sesuai untuk meminimumkan populasi terinfeksi diberikan oleh persamaan berikut ini:

$$
J(u)=\int_{0}^{t_{f}}\left(A I+B u^{2}\right) d t
$$

dengan parameter $A \geq 0$ merupakan bobot populasi terinfeksi dan $B \geq 0$ merupakan bobot biaya kontrol vaksinasi. Untuk mendapatkan pengontrol $u$ tersebut gunakan syarat perlu dan syarat cukup yang sudah dijelaskan pada landasan teori. Berdasarkan fungsi tujuan didefinisikan fungsi Hamilton sebagai berikut.

$$
\begin{aligned}
H= & \left(A I+B u^{2}\right)+q_{1}\left(b N-\frac{\beta I S}{N}-u S-\mu S\right)+q_{2}\left(\frac{\beta I S}{N}-(\mu+\alpha) I\right) \\
& +q_{3}(\alpha I-\mu T-\gamma T)+q_{4}(u S+\gamma T-\mu R) .
\end{aligned}
$$

Berdasarkan persamaan (2.8) diperoleh sebagai berikut:

$$
\begin{gathered}
\dot{q}_{1}=-\frac{\partial H}{\partial S}=\left(\frac{\beta I}{N}+u+\mu\right) q_{1}-\left(\frac{\beta I}{N}\right) q_{2}-u q_{4} \\
\dot{q}_{2}=-\frac{\partial H}{\partial I}=-A+\left(\frac{\beta S}{N}\right) q_{1}-\left(\frac{\beta S}{N}-\mu-\alpha\right) q_{2}-\alpha q_{3} \\
\dot{q}_{3}=-\frac{\partial H}{\partial T}=(\mu+\gamma) q_{3}-\gamma q_{4} \\
\dot{q}_{4}=-\frac{\partial H}{\partial R}=\mu q_{4} \\
q_{1}\left(t_{f}\right)=q_{2}\left(t_{f}\right)=q_{3}\left(t_{f}\right)=q_{4}\left(t_{f}\right)=0 \\
\frac{\partial H}{\partial u}=2 B u-q_{1} S+q_{4} S=0, \quad \text { menghasilkan } u^{*}=\frac{\left(q_{1}-q_{4}\right) S}{2 B} .
\end{gathered}
$$

Karena variabel $u \in[0,1]$, diperoleh kontrol optimal sebagai berikut.

$$
u^{*}=\min \left\{\max \left(0, \frac{\left(q_{1}-q_{4}\right) S}{2 B}\right), 1\right\} \text {. }
$$

Dapat diperiksa bahwa $\frac{\partial^{2} H}{\partial u^{2}}=2 B>0$, yang menunjukkan bahwa $u^{*}$ meminimumkan $J$.

\subsection{Simulasi Numerik}

Pada subbab ini akan dibahas mengenai simulasi numerik untuk mengetahui perilaku solusi model penyakit Tuberkulosis dengan vaksinasi. Pada simulasi ini digunakan model dengan variabel-variabel tak bebas menyatakan proporsi populasi. Hal ini sama saja dengan mengatakan $N=1$ pada model (3.2). Untuk nilainilai awal yang digunakan yaitu $S(0)=0.2921, I(0)=0.2921, T(0)=0.2921$ dan $R(0)=0.1237$ dan nilai-nilai parameter yang diberikan, yaitu $N=1$, $b=0.45, \mu=0.1, \beta=0.5, \alpha=0.3, \gamma=0.85, A=0.25 \operatorname{dan} B=$ 0.5 dengan waktu awal $t_{0}=0$ hari dan waktu akhir $t_{f}=60$ hari [4]. 

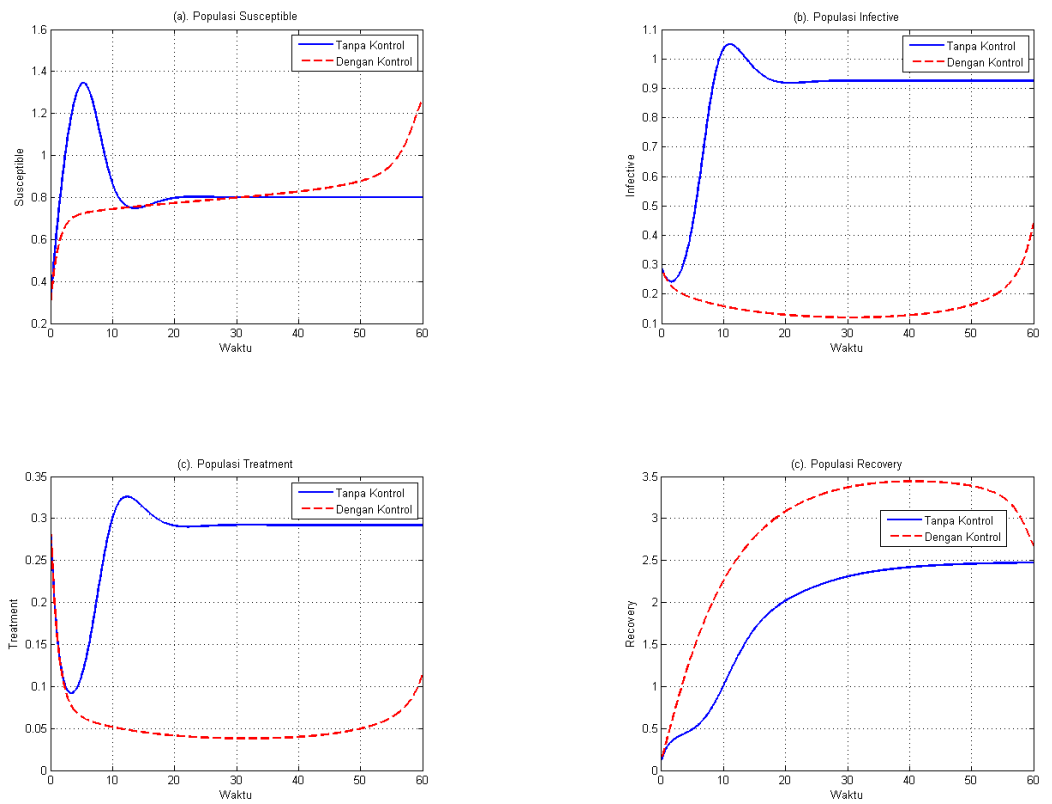

Gambar 1. Grafik populasi Suscuptible, Infective, Treatment dan Recovery

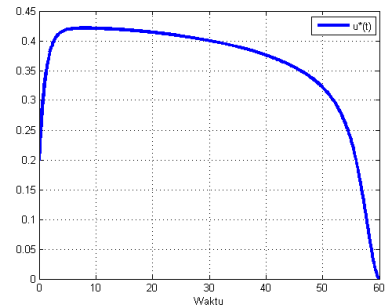

Gambar 2. Grafik kontrol optimal Vaksinasi $\left(u^{*}\right)$

Pada Gambar 1(a) dapat diamati bahwa jumlah populasi rentan dengan kontrol vaksin terjadi peningkatan yang cukup signifikan hingga hari ke-60. Gambar 1(b) dapat diamati bahwa populasi yang terinfeksi penyakit dengan pemberian kontrol vaksin mengalami penurunan yang cukup signifikan. Gambar 1(c) dapat diamati bahwa populasi terinfeksi yang diobati setelah diberi kontrol jumlah populasi terinfeksi yang diobati mengalami penurunan. Namun pada saat hari ke-40 hingga hari ke-60 populasi yang terinfeksi mengalami peningkatan. Dari Gambar 1(d) menunjukkan bahwa populasi sembuh yang diberi kontrol terjadi peningkatan yang lebih cepat dan lebih besar dari pada tanpa pengontrol. Pada Gambar 2 menunjukkan bahwa pemberian vaksinasi $u$ mengalami peningkatan pada saat waktu hari ke- 5 dan mengalami penurunan yang signifikan hingga mencapai nol. Hal ini menunjukkan bahwa tidak ada lagi vaksinasi yang diberikan pada akhir periode. 


\section{Kesimpulan}

(1) Dalam model penyebaran penyakit Tuberkulosis tanpa kontrol terdapat dua titik ekuilibrium, yaitu titik ekuilibrium bebas penyakit $E_{0}=\left(\frac{b N}{\mu}, 0,0,0\right)$ dan titik ekuilibrium endemik $E^{*}=\left(S^{*}, I^{*}, T^{*}, R^{*}\right)$, dengan:

$S^{*}=\frac{(\mu+\alpha) N}{\beta}, I^{*}=\frac{(\beta b-\mu(\mu+\alpha)) N}{\beta(\mu+\alpha)}, T^{*}=\frac{(\beta b-\mu(\mu+\alpha)) \alpha N}{\beta(\mu+\alpha)(\gamma+\mu)}, R^{*}=\frac{\gamma \alpha N(\beta b-\mu(\mu+\alpha))}{\mu \beta(\mu+\alpha)(\gamma+\mu)}$.

Kedua titik ekuilibrium tersebut stabil asimtotik berdasarkan bilangan reproduksi dasar.

(2) Pemberian kontrol optimal untuk meminimalkan jumlah individu terinfeksi berupa $u$ yang merepresentasikan tingkat pemberian vaksin pada individu yang rentan. Diperoleh bentuk kontrol optimal pada model penyebaran penyakit Tuberkulosis yaitu: $u^{*}=\min \left\{\max \left(0, \frac{\left(q_{1}-q_{4}\right) S}{2 B}\right), 1\right\}$. Berdasarkan hasil simulasi pada Matlab menunjukkan bahwa perilaku model dan keefektifan pengontrol vaksinasi pada waktu 0 sampai 30 hari dapat mengurangi populasi yang terinfeksi sehingga dapat mengendalikan penyebaran penyakit Tuberkulosis.

\section{Ucapan Terima kasih}

Penulis mengucapkan terima kasih kepada Bapak Dodi Devianto, Bapak Mahdhivan Syafwan, dan Bapak Efendi yang telah memberikan masukan dan saran sehingga artikel ini dapat diselesaikan dengan baik.

\section{Daftar Pustaka}

[1] Kelley, Walter G. dan Allan C. Peterson. 2010. The Theory of Differential Equation. Second Edition. New York : Springer.

[2] Lenhart, S., and J.T. Workman. 2007. Optimal Control Applied to Biological Models. Chapman and Hall, CRC Press. New Work.

[3] Olsder, G.J and Woude, J.W. Van Der. (2004). Mathematical Systems Theory. Delft University of Technology.

[4] P. Anita, Kamiran, dan N. Aisyah, Analisis Kestabilan dan Kontrol Optimal Model Penyebaran Tuberkulosis dengan Terapi dan Vaksinasi Menggunakan Metode Runge Kutta. J. Sains dan Seni. 2019.

[5] Rost, G. and Jianhong, Wu. 2008. SEIR Epidemiological Model with Varying Infectivity and Infinite Delay. Mathematical Biosciences and Engineering. Vol. 5. No. 2. 389-402.

[6] S. Naidu. 2002. Optimal Control System. USA: CRC Pres.

[7] S. Side, W. Sanusi, and N. F. Setiawan. 2016. Analisis dan Simulasi Model SITR pada Penyebaran Penyakit Tuberkulosis di Kota Makassar. J. Sainsmat, pp. 191204.

[8] Subiono. 2016. Sistem Linear dan Kontrol Optimal. Versi 2.2.1, Surabaya.

[9] World Health Organization, Global Tuberculosis Report 2014. 2014. 